\title{
A Nobel Day in Lisbon, Portugal - A Unique Experience for Someone who Loves Science
}

Catarina Alves-Vale.

\section{The Experience}

About the Author: Catarina Alves-Vale is a third-year medical student (Faculdade de Medicina, Universidade de Lisboa, Portugal) of a six-year course. She is also doing research about regulation of gene expression at Instituto de Medicina Molecular (Lisboa). In 2013, Catarina won the prize for the Best Plenary Presentation at the An nual International Medical Students Meeting (AIMS Meeting).
Submission: Sep 9, 2013 Acceptance: Jan 15, 2014
June 25th 2013. I will never forget that sunny and busy day in Lisbon, Portugal. After exiting the subway and walking for a few minutes, a huge and magnificent building in the middle of the city appeared on my horizon. It was there, in Culturgest, where I had the opportunity to listen and learn from a group of eminent scientists and Nobel Laureates in physiology and medicine. "A Nobel Day in Lisbon" was an open event supported by Cunha Vaz Associates, a leading communication company, and hosted by Renata Gomes who is a reputed Portuguese scientist affiliated with the University of Oxford and the University College London, who is interested in nanotechnology for cardiovascular regeneration (Cunha Vaz Associates. A Nobel Day. Available from: http://www.anobelday.com/. Cited 2013 Sep 5).

The morning topics included discussion regarding the financial difficulties in science and the future of scientific research, which were explored through panel discussions addressed to the public. Basically, the scientists talked to the audience about their work and career, their feelings towards science and how they deal with roadblocks. In some cases, what they were talking about could be applied to areas outside of medicine, in everyday life. For example, many interventions focused on the importance of thinking outside the box when we are trying to plan the future, like a new research project. However, this also should happen when we need to find a key to solve problems, which are quite usual in science, but provide great opportunities to make changes in the way we work and think. Furthermore, it was highlighted, for several times, that being sufficiently persistent to pursue our goals, and specially our dreams, is a requirement to be successful. Another discussed topic was the responsibility of scientists to communicate with society the relevance of their work and discoveries because all the citizens are contributing to the public science funding.

During the afternoon, more specific scientific sessions took place. We had to choose between two "Professional Sessions", because they would be occurring at the same time in different places. I chose the "Vascular Science" session, in which Professor Paul Riley, director of the Oxbridge British Heart Foundation Centre of Regenerative Medicine and Chair of Development and
Reproduction at University of Oxford, told us about his research "en route to mend a broken heart" (University of Oxford. Paul Riley - Oxford Cardiovascular Science. Available from: http:// www.cardioscience.ox.ac.uk/bhf-centre-of-research-excellence/ researcher-profiles/paul-riley. Cited 2013 Sep 6). Specifically, Professor Riley explained how his team used stem cells to treat ischaemic cardiac disease, the leading cause of mortality worldwide (World Health Organization, WHO. The top 10 causes of death. 2013. Available from: http://who.int/mediacentre/ factsheets/fs310/en/. Cited 2013 Sep 5). ' The presentation that I enjoyed the most was integrated in this session "Where do Ideas Come From". It was given by Professor Oliver Smithies, Excellence Professor of Pathology and Laboratory Medicine at University of North Carolina and the Nobel Prize laureate in 2007 for introducing starch as a medium in gel electrophoresis (Smithies 0. Turning Pages. In: Grandin K, editor. Les Prix Nobel. The Nobel Prizes 2007. Stockholm; 2008. Available from: http:// www.nobelprize.org/nobel_prizes/medicine/laureates/2007/ smithies_lecture. Cited 2013 Sep 5). Professor Smithies, a very kind and enthusiastic 88-year old scientist, also provided advice to the audience in the room; for instance the importance of keeping appropriate lab-book notes and choosing to work in a subject that you really enjoy. I found myself asking what keeps Professor Smithies going? According to his own testimony, it is simply curiosity.

As a second year medical student, and an aspiring scientist, having the possibility of learning with reputed scientists was an amazing opportunity. I was lucky because the Instituto de Medicina Molecular, Lisbon, advertised the event among collaborators, including undergraduate students conducting research. There is still a long way to go to successfully convey to society what scientists actually do. It is really important that scientists themselves strive to be active players in the communication of science to the general audience. This unique day was a very positive step, but more of these steps are needed, and I wish to be part of them.

${ }^{1}$ Medical student, Faculdade de Medicina, Universidade de Lisboa, Lisboa, Portugal 


\section{Experience}

\section{References}

1. Bollini S, Smart N, Riley PR. Resident cardiac progenitor cells: At the heart

of regeneration. J Mol Cell Cardiol. 2011 Feb;50(2):296-303

\section{Acknowledgments}

I am grateful to Noélia Custódio for reading the manuscript.

Conflict of Interest Statement $\mathrm{c}$ Funding

The authors have no funding, financial relationships or conflicts of interest to disclose.

Author Contributions

Write the manuscript: CAV

\section{Cite as:}

Alves-Vale C. A Nobel Day in Lisbon, Portugal - A Unique Experience for Someone who Loves Science. Int J Med Students. 2014 MarJun;2(2):74-5. 